\title{
Dysphagia in head and neck cancer patients following intensity modulated radiotherapy (IMRT)
}

\author{
Evangelia Peponi ${ }^{1}$, Christoph Glanzmann ${ }^{1}$, Bettina Willi ${ }^{2}$, Gerhard Huber ${ }^{3}$, Gabriela Studer ${ }^{1 *}$
}

\begin{abstract}
Background: To evaluate the objective and subjective long term swallowing function, and to relate dysphagia to the radiation dose delivered to the critical anatomical structures in head and neck cancer patients treated with intensity modulated radiation therapy (IMRT, +/- chemotherapy), using a midline protection contour (below hyoid, $\sim$ level of vertebra 2/3).

Methods: 82 patients with stage III/IV squamous cell carcinoma of the larynx, oropharynx, or hypopharynx, who underwent successful definitive ( $n=63$, mean dose 68.9Gy) or postoperative ( $n=19$, mean dose 64.2Gy) simultaneous integrated boost (SIB) -IMRT either alone or in combination with chemotherapy (85\%) with curative intent between January 2002 and November 2005, were evaluated retrospectively. 13/63 definitively irradiated patients (21\%) presented with a total gross tumor volume (tGTV) > 70cc (82-173cc; mean 106cc). In all patients, a laryngo-pharyngeal midline sparing contour outside of the PTV was drawn. Dysphagia was graded according subjective patient-reported and objective observer-assessed instruments. All patients were re-assessed 12 months later. Dose distribution to the swallowing structures was calculated.
\end{abstract}

Results: At the re-assessment, 32-month mean post treatment follow-up (range 16-60), grade 3/4 objective toxicity was assessed in $10 \%$. At the 32-month evaluation as well as at the last follow up assessment mean 50 months (16-85) post-treatment, persisting swallowing dysfunction grade 3 was subjectively and objectively observed in 1 patient (1\%). The 5-year local control rate of the cohort was 75\%; no medial marginal failures were observed.

Conclusions: Our results show that sparing the swallowing structures by IMRT seems effective and relatively safe in terms of avoidance of persistent grade $3 / 4$ late dysphagia and local disease control.

\section{Background}

Limited data are available on the long term swallowing function in intensity modulated radiotherapy (IMRT) treated patients at risk for dysphagia [1-3].

We aimed to evaluate the objective and subjective long term swallowing function, and to relate dysphagia to the radiation dose delivered to the critical anatomical structures in our consecutively IMRT (+/- chemotherapy) treated head and neck cancer patients.

We focused on serious subjective as well as objective symptoms (grade $3 / 4$ late effects).

\footnotetext{
* Correspondence: gabriela.studer@usz.ch

'Department of Radiation Oncology, University Hospital Zurich, Zurich, Switzerland

Full list of author information is available at the end of the article
}

\section{Methods}

Patient, disease and staging characteristics

A total of 82 out of 96 eligible patients 'at risk' for dysphagia due to a stage III/IV squamous cell carcinoma of the larynx, oropharynx or hypopharynx agreed to participate in our retrospective assessment. All included patients were successfully treated with curative intent by simultaneous integrated boost (SIB)-IMRT either alone or in combination with chemotherapy or surgery at our department between January 2002 and November 2005. Seventy patients $(85 \%)$ received concurrent cisplatin chemotherapy $(40 \mathrm{mg} / \mathrm{m} 2$ i. v. weekly).

Exclusion criteria included loco-regional recurrence at the time of assessment of swallowing dysfunction, a follow-up period $<4$ months at the first assessment,

\section{Biomed Central}


patients having tracheostomy tubes and/or laryngectomy, and loco-regional tumor stage $\leq \mathrm{T} 1 / 2 \mathrm{~N} 0$.

Analysis has been performed after institutional research ethics board approval. First, EORTC questionnaires regarding quality-of-life (QOL) and SOMA LENT scale regarding late toxicity accompanied with an informed consent form were mailed out to the patients, who were already informed by phone. The subjective answers resulted from a first assessment (mean 20 months; range: 4-40 months), based on a questionnaire for each patient. All patients -with special consideration to those presenting with late toxicity $>$ grade 2 - have been re-assessed objectively one year later (mean 32 months, range 16-60). The 5 year local disease control and dysphagia grade $3 / 4$ rates were based on the most recent follow up assessment ('last time seen').

Included in this analysis were 19 consecutive eligible patients treated in the indicated time period, who underwent surgery (without tracheostomy or laryngectomy) followed by postoperative IMRT, as the postoperative set up was considered similarly 'risky' for the development of late term dysphagia (fibrosis, edema), and of additional informative value.

In addition, one interesting case of a patient who underwent contra-lateral cobalt irradiation 30 years ago was also included. This patient with a T3N2b lateral oropharynx cancer experienced grade 4 dysphagia at the subjective assessment. She received total IMRT dose of 69.6Gy unilaterally (daily dose: $2.11 \mathrm{~Gy}$ ) and 5 cycles of concurrent cisplatin, after having been irradiated 30 years ago to the contra-lateral neck and tonsil with a total dose of $60 \mathrm{~Gy}$ by a $\mathrm{Co}^{60}$; the cumulative dose received by the swallowing structures could not be estimated. Esophagus dilatations achieved temporary results; however, although she remains PEG dependent, she is able to swallow her saliva, and remained disease free at the 4-year follow-up visit.

All patients were staged using the 2002 American Joint Committee on Cancer (AJCC) criteria [4]. Patient and disease characteristics are listed in Table 1. Mean age of the cohort was 61 years (range 34-80). Volumetric staging is shown in Table 2.

\section{Evaluation and scoring of late toxicity}

Normal tissue effects were graded according to the Radiation Therapy Oncology Group (RTOG)/European Organization for Research and Treatment of Cancer (EORTC) radiation morbidity scoring criteria [5].

Swallowing dysfunction and dysphagia were additionally graded with subjective patient-reported and objective observer-assessed instruments. Patient-reported clinical swallowing function was evaluated using the "European Organization for Research and Treatment of Cancer (EORTC) head-and-neck 35-item swallowing
Table 1 Patient and disease characteristics $(n=82)$

\begin{tabular}{lrcc}
\hline Characteristics & & No of patients & $\%$ \\
\hline Gender & Male & 68 & 83 \\
& Female & 14 & 17
\end{tabular}

Primary site

$\begin{array}{rcc}\text { Oropharynx central } & 26 & 32 \\ \text { Oropharynx lateral } & 29 & 35 \\ \text { Hypopharynx } & 18 & 22 \\ \text { Larynx } & 9 & 11\end{array}$

Stage III/IV

82

100

RT intention

$\begin{array}{rll}\text { primary } & 63 & 77 \\ \text { postoperative } & 19 & 23\end{array}$

$\begin{array}{lll}\text { Concomitant CT } & 70 & 85\end{array}$

$\begin{array}{lll}\geq 4 \text { cycles } & 63 & 77\end{array}$

previous RT

1

1

Abbreviations: No: number, RT: Radiotherapy. CT: Chemotherapy.

and aspiration (QLQ-H\&N35)" quality-of-life (QOL) questionnaire.

Observer-assessed dysphagia was assessed according to the SOMA LENT scale for head-and-neck carcinoma radiotherapy objective criteria (German Version). During the course of irradiation, all patients were clinically assessed at regular weekly intervals, and 2 weeks to 2 months after completion of treatment. Four to 6 weeks after completion of IMRT, all patients were also seen regularly in our joint clinic at the Department of Head and Neck Surgery. Institutional standards for patient assessment included physical examination with additional flexible fiberoptic endoscopy at the Department of Head and Neck Surgery approximately every 2 months in the first year of follow-up, every 3 months in the second to third year and every 6 months in the fourth to fifth year.

\section{Treatment characteristics}

Patients were immobilized from head to shoulders with commercially available thermoplastic masks in the supine position. CT images (2 $\mathrm{mm}$ slice thickness) were acquired from the top of the vertex to the level of the carina with contrast agent infusion in non-operated patients.

We used an extended-field IMRT (EF-IMRT) technique, where the primary tumor was treated in one phase along with the regional lymph nodes. Irradiation was delivered with five or seven coplanar beam angles by a 
Table 2 Volumetric staging in patients treated with primary radiotherapy $(n=63)$

\begin{tabular}{|c|c|c|c|c|}
\hline \multirow[b]{2}{*}{ Primary site } & \multicolumn{4}{|c|}{ total gross tumor volume (tGTV) } \\
\hline & mean (range) & $1-15 c c$ & $16-70 \mathrm{cc}$ & $>70 \mathrm{cc}$ \\
\hline \multicolumn{5}{|l|}{ Oropharynx } \\
\hline base of tongue & $34 c c(9-127 c c)$ & 2 & 13 & 3 \\
\hline tonsil/lateral mesopharynx & $51 \mathrm{cc}(4-171 \mathrm{cc})$ & 1 & 11 & 7 \\
\hline
\end{tabular}

Larynx

\begin{tabular}{rcccc} 
Glottis & $12 c c(1-29 c c)$ & 1 & 1 & 0 \\
Supraglottis & $21 c c(6-54 c c)$ & 2 & 5 & 0 \\
& $46 c c(5-173 c c)$ & 3 & 11 & $\mathbf{1 3 ( 2 1 \% )}$ \\
\hline
\end{tabular}

6-MV dynamic MLC system (sliding window technique) (Varian Medical Systems, CA).

As previously described [1] an accelerated SIB- IMRT technique was performed with a daily dose of 2.00 2.35Gy (total dose: 63-75Gy) to the primary tumor and positive neck nodes in the definitive RT cases $(n=63)$ and a daily dose of 1.80-2.00Gy to a total dose of 60$66 \mathrm{~Gy}$ in postoperative cases $(\mathrm{n}=19)$. For intensity optimization the prescribed dose should encompass at least 95\% of the PTV. Additionally, no more than $20 \%$ of any PTV would receive $>110 \%$ of its prescribed dose, while no more than $1 \%$ of any PTV would receive $<93 \%$ of the desired dose. The mean total treatment time was 45.3 days (32-55 days).

The protection of anatomical swallowing structures was routinely performed by drawing a laryngo-pharyngeal midline 'shielding' contour outside the PTVs in all cases. This sparing structure has been defined prospectively in January 2002, when we implemented IMRT clinically, and was provided to be used in all midline areas where no PTV was required. This structure may include esophageal, laryngeal, and pharyngeal structures. Aimed dose constraint for this midline shielding was a mean dose (Dmean) below 45Gy (Figure 1).

In oropharyngeal cancer patients, this structure was usually contoured from the level of the hyoid (below the lateral retropharyngeal lymph nodes, corresponding $\sim$ to the cervical vertebra $2 / 3$, Figure 1 ) to the lowest level at which PTVs were drawn. In hypopharyngeal cancer patients, midline protection is often limited to some aspects of the larynx to just prevent laryngeal structures from full tumor dose.

\section{Clinical factors}

The clinical variables examined for correlation with grade 3-4 late toxicity included age, gender, primary site, tumor stage, tumor volume, therapy sequence, addition of systemic therapy and IMRT treatment schedules.

\section{Dosimetric factors}

The dose distribution to the swallowing structures was calculated on the original IMRT treatment plans. Based

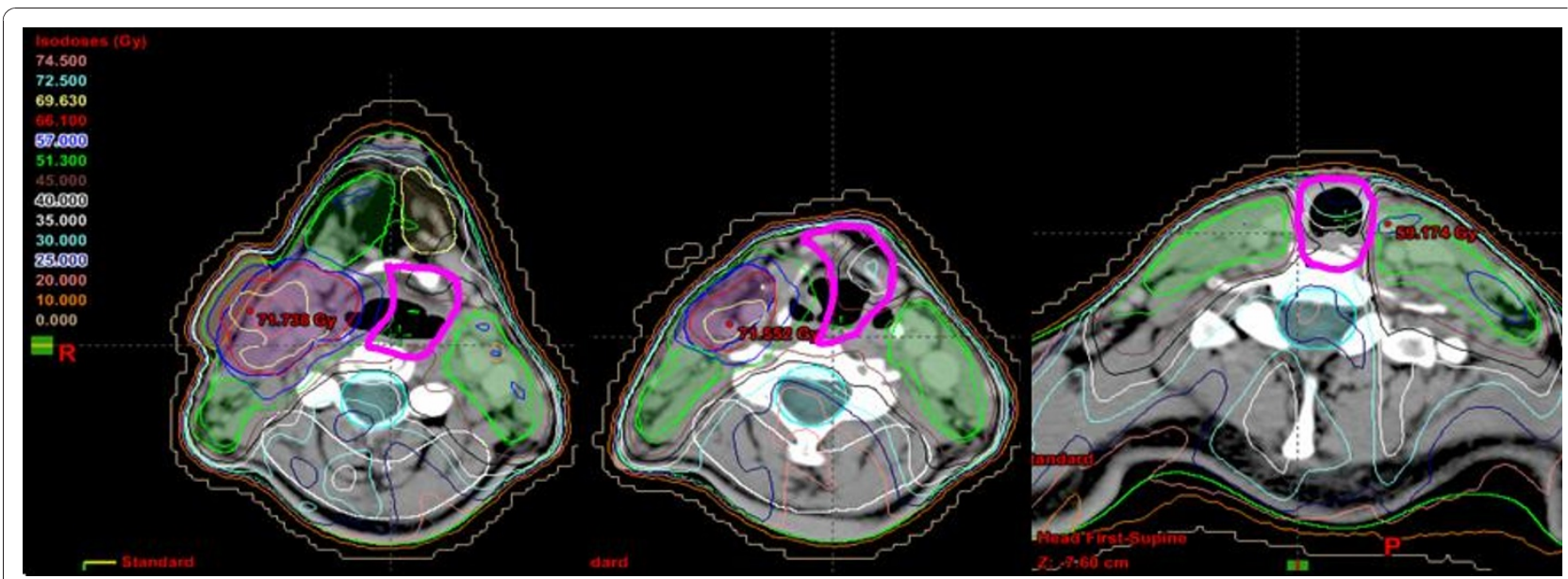

Figure 1 Example: midline shielding as used according to our internal IMRT guidelines (pink contour, below hyoid/C3). 
on studies published so far [6-9], and with regard to the swallowing apparatus, the following anatomic structures were retrospectively identified and delineated on the axial CT-slices of each plan: the pharyngeal constrictor muscles (PCs) - superior, middle and inferior-, the glottic and supraglottic larynx (GSL) and the muscular compartment of the esophagus inlet (eim). In brief, the superior constrictor muscle $(\mathrm{scm})$ was defined from the caudal tips of the pterygoid plates through the upper edge of the hyoid bone, the middle constrictor muscle $(\mathrm{mcm})$ was defined from the upper through the lower edge of the hyoid and the inferior constrictor muscle (icm) was defined from below the hyoid through the inferior edge of the cricoid. A structure named PCs was outlined to involve the constrictors as a single structure. The larynx (GSL) was contoured from the tip of the epiglottis superiorly to the bottom of the cricoid inferiorly. Caudal to the inferior border of the cricoid, the esophagus (eim) was contoured, with its caudal-most extent corresponding to the caudal-most extent of the low neck target volumes. Dose-volume histograms to the swallowing structures were assessed and mean dose, maximum point dose (Dmax), minimum point dose (Dmin), $V_{30}$ (volume of a structure receiving $>30 G y$ ), $\mathrm{V}_{50}$ (volume of a structure receiving $>50 \mathrm{~Gy}$ ), $\mathrm{V}_{60}$ (volume of a structure receiving $>60 \mathrm{~Gy}$ ), $\mathrm{V}_{65}$ (volume of a structure receiving $>65 \mathrm{~Gy}$ ), $\mathrm{V}_{70}$ (volume of a structure receiving $>70 \mathrm{~Gy}$ ), $\mathrm{D}_{50}$ (dose received by $50 \%$ volume of a structure/median dose) and $\mathrm{D}_{80}$ (dose received by $80 \%$ volume of a structure) were calculated.

\section{Statistical analysis}

Statistical calculations of Kaplan Meier curves were performed using StatView ${ }^{\circledR}$ program (Abacus Concepts
Inc., Berkeley, CA). A $p$ value of $\leq 0.05$ was considered statistically significant.

\section{Results}

Between January 2002 and November 2005, a total of 82 out of 96 eligible patients successfully treated with SIBIMRT agreed to participate in our study. 80 patients responded to all given questionnaires; $2 / 82$ patients declined to return the questionnaires, however, agreed to allow using their objective data as assessable from regular follow up visits. One previously irradiated patient was excluded from the dysphagia analysis.

\section{Late toxicity}

At the first post-treatment follow-up (mean 20 month, range 4-48), any subjective grade $3 / 4$ toxicity (G3/4) was reported by $14 / 80$ patients (18\%), while $66 / 80$ patients (82\%) experienced grade $0-2$ toxicity. At the second follow up (objective assessment), grade $3 / 4$ toxicity rate was $10 \%$ (8/78) (two patients excluded because of tumor recurrence, two patients lost to follow-up); Table 3 shows subjective and objective late toxicity. The mean dose and dose range in definitively irradiated versus postoperatively irradiated patients is indicated in Table 1.

\section{Prevalence of long term dysphagia (re-irradiated patient excluded)}

At the patient reported first assessment (mean 20 months, range 4-40), 77/79 patients experienced dysphagia grade $0-2$; five patients (8\%) experienced dysphagia grade 2 , symptom that continued to persist only in one patient by reevaluation (objective assessment, mean 32 months, range 16-60). Persistent dysphagia grade $3 / 4$ was found in one patient (1\%). There were no cases of

Table 3 Frequency of grade 3/4 (G3/4) late toxicity at the subjective (mean 20 months; range 4-40) and objective (mean 32 months; range 16-60) assessment

\begin{tabular}{|c|c|c|c|}
\hline \multirow[b]{2}{*}{ Parameter } & \multicolumn{3}{|c|}{ Grade $3 / 4$ late term toxicity } \\
\hline & \multicolumn{2}{|r|}{ Subjective } & \multirow{2}{*}{$\frac{\text { O b j e c t i ve }}{\text { na }}$} \\
\hline Swallow pain & 1 & & \\
\hline Dysphagia & 2 & (1 definitive/1 postoperative) & 2 (same pts. as subjective) \\
\hline Taste alteration & 9 & & na \\
\hline \multirow[t]{2}{*}{ Xerostomia } & 3 & & 6 \\
\hline & & & (same 3 pts as subjective +3 others) \\
\hline Weight loss $\geq 10 \%$ & na & & 0 \\
\hline Hoarseness & 0 & & 0 \\
\hline Total No of pts & $14 / 80($ & & $8 / 78(10 \%)$ \\
\hline
\end{tabular}

Abbreviations: na: not assessable, pts: patients, No: number 
clinically symptomatic pneumonia as a potential consequence of aspiration reported by patients or stated in the patient charts (no radiological swallowing tests performed).

At the second evaluation (mean 32 month post treatment; n loco-regionally controlled patients with no previous radiation $=77$ ) as well as at the most recent follow up ("patient last seen", mean 50 months, range 16-85, Figure 2), persisting swallowing dysfunction grade (2-) 3 was subjectively and objectively assessed by 1 patient.

\section{Weight loss/PEGs}

Percutaneous endoscopic gastrostomy feeding tubes (PEGs) were placed before or during treatment in 21 of 82 patients $(26 \%)$. The mean time to PEG tube removal was 8 months (range 5-25). At the time of the first analysis (20-month follow up), 6/21 patients (7\% of all, 1/3 of the PEG patients) were still using PEG for some or all of their nutrition. Patients sustained median weight loss of $5.1 \mathrm{~kg}$ (range $0-20 \mathrm{~kg}$ ) during treatment, while one year post treatment there was no patient who had lost $>10 \%$ of body weight. Only two of those 6 patients remained PEG-dependent (10\% of all PEG patients, $2 \%$ of the entire cohort); the other 4 patients regained independence of PEG 14, 16, 33 and 36 months after completion of IMRT, respectively. In none of the patients who remained loco-regionally disease free, a PEG had to be placed during the monitored follow up period/replaced once the PEG has been removed.

\section{Swallowing structure doses}

The median doses (median of the median dose) to the swallowing structures, the partial volumes receiving specified doses $\left(\mathrm{V}_{\mathrm{D}}\right)$ in all patients and comparable results of reported series are detailed in Tables 4 and 5 .

\section{Long term local control and overall survival}

The 3 and 5 year local control rates of the assessed cohort were 78 and $75 \%$ (Figure 2), the corresponding

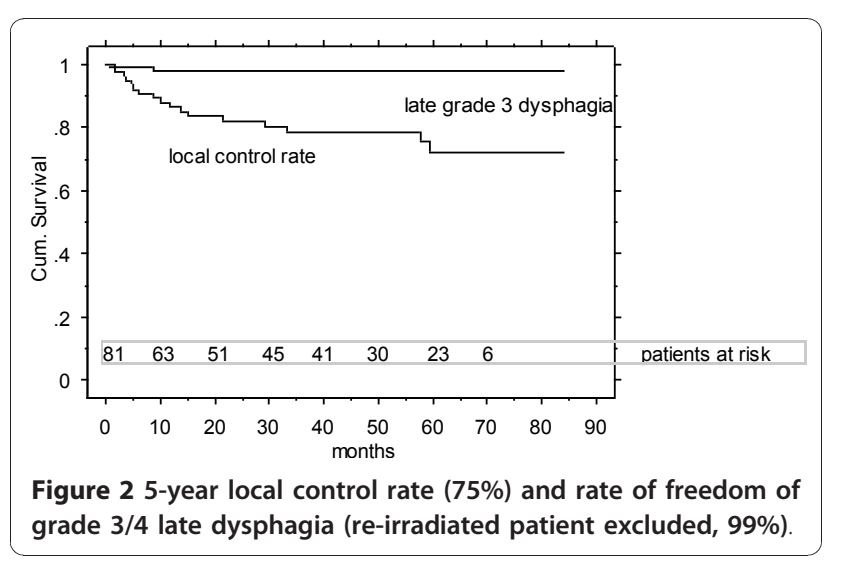

overall survival rates were 80 and $77 \%$, respectively (Kaplan Meier survival curves, December 2010). None of the local failures were found related to the midline protection structure (all failures analysed: no medial marginal failures).

\section{Discussion}

Recent gains in the management of head and neck cancer have been achieved due to concurrent chemo-radiotherapy with altered fractionated three-dimensional conformal radiotherapy (3D-CRT) or IMRT technique [10-12]. The use of these high intensity treatments has resulted in considerable rates of swallowing dysfunction, both acute (15-63\%) and long term (3-21\%) [13-20]. Comprehensive data on late toxicity from randomized and nonrandomized trials, however, are sparse.

In our cohort of patients treated with SIB-IMRT either alone or in combination with chemotherapy or surgery, the rate of grade 3/4 long term dysphagia was $1 \%$, comparable to that seen in other IMRT studies, and considerably better than that observed in 3D-CRT studies (Table 6). These findings of a low rate of severe dysphagia in a patient cohort at risk motivate efforts to reduce the doses to the swallowing structures, fact which could reduce the severity and prevalence of dysphagia. This may be reached by a simple protection structure along the midline were no PTV is needed (Figure 1). Analysis of the relationship between the swallowing structure doses and the development of late dysphagia were limited due to the single event, precluded statistical significance. Median doses of the swallowing structures in the own cohort were comparable to reported series [7,21] (Table 4,5). The limitation of our study was the retrospective nature of the analysis, whereas midline protection contouring (Figure 1) was prospectively performed as part of our internal IMRT guidelines. Similar to the parotid gland protection, no oncological compromises are acceptable in contouring the midline sparing structure. The group of Eisbruch et al [2] suggested that the high loco-regional control rates have not been compromised by the efforts to spare the parts of the swallowing structures not involved by tumor and not at risk of subclinical disease. In addition, in a previous evaluation of our hypopharynx-larynx patient cohort [22] treated with IMRT using midline sparing as far as feasible, local failures were not found related to the midline sparing structures.

The low percentage of PEG tube dependence (7\%) at the mean 20-month follow-up may be interpreted as a surrogate of limited swallowing problems.

Published analyses focused on predicting the probability of severe acute or late dysphagia during or after RT $[23,24]$ between patient-rated and objective assessment of dysphagia are conflicting. 
Table 4 Median doses (median of the median dose) to the swallowing structures in all patients and comparison to reported series

\begin{tabular}{|c|c|c|c|c|c|c|c|}
\hline \multicolumn{2}{|c|}{ Swallowing structures } & \multicolumn{2}{|c|}{ Current study } & \multicolumn{2}{|c|}{ Feng et al 2007 [21] } & \multicolumn{2}{|c|}{ Levendag et al* 2007 [7] } \\
\hline & & Median & Range & Median & Range & Median & Range \\
\hline \multirow[t]{2}{*}{ PCs } & Volume (cc) & 20 & $11-32$ & NA & NA & NA & NA \\
\hline & Dose (Gy) & 59 & $39-66$ & 64 & $51-72$ & 48 & $6.0-73.0$ \\
\hline \multirow[t]{2}{*}{$\mathrm{scm}$} & Volume (cc) & 12 & $6-21$ & NA & NA & NA & NA \\
\hline & Dose (Gy) & 59.4 & $24-69$ & 68 & $57-74$ & 51 & $22.0-73.0$ \\
\hline \multirow[t]{2}{*}{$\mathrm{mcm}$} & Volume (cc) & 3.6 & $1.5-9$ & NA & NA & NA & NA \\
\hline & Dose (Gy) & 59 & $37.0-71.5$ & 64 & $53-75$ & 48 & $11.0-72.0$ \\
\hline \multirow[t]{2}{*}{$\mathrm{icm}$} & Volume (cc) & 3.7 & $0.9-7$ & NA & NA & NA & NA \\
\hline & Dose (Gy) & 53 & $29-73$ & 51 & $30-70$ & 32 & $6.0-73.0$ \\
\hline \multirow[t]{2}{*}{ GSL } & Volume (cc) & 15.3 & $6.4-23$ & NA & NA & NA & NA \\
\hline & Dose (Gy) & 53 & $28-70$ & 55 & $22-72$ & NA & NA \\
\hline \multirow[t]{2}{*}{ eim } & Volume (cc) & 5.4 & $0.7-44$ & NA & NA & NA & NA \\
\hline & Dose (Gy) & 39 & $16.0-67.8$ & 44 & $15-66$ & 18 & $3.0-64.0$ \\
\hline
\end{tabular}

*The results are not entirely comparable with the study of Levendag et al [7], as there is a difference in the delineation of muscular structures. In Levendag et al. the anterior part of $\mathrm{scm}$ and $\mathrm{mcm}$ were not delineated and eim was defined as the proximal $1 \mathrm{~cm}$ of the esophageal inlet, regardless of the caudal-most extent of the low neck target volumes.

Abbreviations: PCs: pharyngeal constrictor muscles, scm: superior constrictor muscle, mcm: middle constrictor muscle, icm: inferior constrictor muscle, GSL: glottic and supraglottic larynx, eim: muscular compartment of the esophagus inlet, NA: not assessed

Table 5 Partial volumes receiving specified doses (VD) to the swallowing structures in all patients and comparison to the data as reported by Feng et al 200721

\begin{tabular}{|c|c|c|c|c|c|c|c|c|c|c|c|}
\hline & \multicolumn{4}{|c|}{ PCs, median (range) } & \multicolumn{4}{|c|}{ GSL, median (range) } & \multicolumn{3}{|c|}{ eim, median (range) } \\
\hline & V50 (\%) & V60 (\%) & V65 (\%) & V70 (\%) & V50 (\%) & V60 (\%) & V65 (\%) & V70 (\%) & V50 (\%) & V60 (\%) & V65 (\%) \\
\hline Current study & $88.5(10-100)$ & $43.9(0-94)$ & $29(0-60)$ & $7.3(0-40)$ & $3.9(1-100)$ & $21.1(0-98)$ & $8.9(0-94)$ & $0(0-67)$ & $5.1(0-100)$ & $0(0-87)$ & $0(0-84)$ \\
\hline Feng et al [21] & $90(58-100)$ & $73(36-100)$ & 57 (20-99) & NA & $69(1-100)$ & $37(0-100)$ & $20(0-100)$ & NA & $14(0-100)$ & $0(0-100)$ & $0(0-78)$ \\
\hline
\end{tabular}

Abbreviations: PCs: pharyngeal constrictor muscles, GSL: glottic and supraglottic larynx, eim: muscular compartment of the esophagus inlet, NA: not assessed.

Table 6 Results from selected series regarding late toxicity in head and neck cancer patients treated with RT \pm chemotherapy

\begin{tabular}{|c|c|c|c|c|c|c|c|}
\hline Technique & $\begin{array}{l}\text { Authors } \\
\text { [reference] }\end{array}$ & year & $\begin{array}{l}\text { No of } \\
\text { patients }\end{array}$ & $\begin{array}{l}\text { median follow up } \\
\text { (months) }\end{array}$ & $\begin{array}{l}\text { stage III/IV } \\
(\%)\end{array}$ & $\begin{array}{l}\text { Chemotherapy } \\
\text { (\%) }\end{array}$ & $\begin{array}{l}\text { grade } 3 / 4 \text { late } \\
\text { toxicity }\end{array}$ \\
\hline & Chao et al [25] & 2003 & 74 & 30 & 93 & 23 & 0 \\
\hline \multicolumn{8}{|l|}{ । } \\
\hline & de Arruda et al [14] & 2006 & 50 & 18 & 92 & 86 & $3(6 \%)$ \\
\hline \multicolumn{8}{|l|}{ M } \\
\hline & Lee et al [17] & 2006 & 41 & 31 & 100 & 100 & $5(12 \%)$ \\
\hline \multicolumn{8}{|l|}{$\mathrm{R}$} \\
\hline & Studer et al [1] & 2006 & 115 & 18 & 52 & 78 & $18(15 \%)$ \\
\hline \multicolumn{8}{|l|}{$\mathrm{T}$} \\
\hline & present study & 2010 & $81^{*}$ & 55 & 100 & 85 & $7(9 \%)$ \\
\hline & Denis et al [26] & 2003 & 44 & 60 & 100 & 61 & $30(68 \%)$ \\
\hline \multicolumn{8}{|l|}{ 3D-CRT } \\
\hline & Huguenin et al [19] & 2004 & 224 & 39 & 97 & 50 & G3: 92 (41\%) \\
\hline & & & & & & & G4: 5 ("\%) \\
\hline
\end{tabular}

Abbreviations: IMRT: Intensity modulated radiation therapy; 3D-CRT: three-dimensional conformal radiotherapy (*patient with previous Cobalt radiation therapy excluded). 
Patients' satisfaction with their swallowing function, in addition with the objective parameters 'body weight' and 'dependency of a long term PEG', are reliable answer and were found congruent with the objective grading. No specific tests were performed to detect potentially aspiration-related, clinically not obvious pneumonia.

\section{Conclusions}

In conclusion, IMRT using a midline contour to spare swallowing structures outside PTVs is relatively safe and effective in terms of local disease control and avoidance of persistent late dysphagia. The subjective patients' estimation of late dysphagia was compatible with the objective assessment of swallowing dysfunction.

\section{Author details \\ ${ }^{1}$ Department of Radiation Oncology, University Hospital Zurich, Zurich, Switzerland. 'Department of Pediatrics, Civic Hospital of Lugano, Lugano, Switzerland. ${ }^{3}$ Department of Otorhinolaryngology, Head and Neck Surgery, University Hospital Zurich, Zurich, Switzerland.}

\section{Authors' contributions}

GS and CG conceived of the study, carried out its design and supervised the coordination. BW performed all phone call interviews with patients, sent out and analysed the QoL questionnaire forms. EP carried out the specific contouring work, analysed the related DVHs, and drafted the manuscript. GH was mainly involved/in charge with the clinical post treatment follow up visits of all patients. All authors read and approved the final manuscript.

\section{Competing interests}

The authors declare that they have no competing interests.

Received: 19 October 2010 Accepted: 5 January 2011

Published: 5 January 2011

\section{References}

1. Studer G, Huguenin PU, Davis JB, Kunz G, Lutolf UM, Glanzmann C: IMRT using simultaneously integrated boost (SIB) in head and neck cancer patients. Radiat Oncol 2006, 1:7.

2. Feng Y, Kim MHyungjin, et al: Intensity-Modulated Chemoradiotherapy Aiming to Reduce Dysphagia in Patients With Oropharyngeal Cancer: Clinical and Functional Results. J Clin Oncol 2010, 28:2732-2738

3. Caudell JJ, Schaner PE, Meredith RF, et al: Factors Associated With LongTerm Dysphagia After Definitive Radiotherapy for Locally Advanced Head-and-Neck Cancer. International Journal of Radiation Oncology*Biology*Physics 2009, 73:410-415.

4. Cooper J, Fleming ID, editors, HD: Head and Neck Cancer. AJCC Manual for Staging of Cancer. 6 edition. Philadelphia: JB Lippincott; 2002.

5. James DC, JoAnn S, Thomas FP: Toxicity criteria of the Radiation Therapy Oncology Group (RTOG) and the European organization for research and treatment of cancer (EORTC). International journal of radiation oncology, biology, physics 1995, 31:1341-1346.

6. Eisbruch A, Schwartz M, Rasch C, et al: Dysphagia and aspiration after chemoradiotherapy for head-and-neck cancer: Which anatomic structures are affected and can they be spared by IMRT? International Journal of Radiation Oncology Biology Physics 2004, 60:1425-1439.

7. Levendag PC, Teguh DN, Voet $P$, et al: Dysphagia disorders in patients with cancer of the oropharynx are significantly affected by the radiation therapy dose to the superior and middle constrictor muscle: A doseeffect relationship. Radiotherapy and Oncology 2007, 85:64-73.
8. Sanguineti G, Adapala P, Endres EJ, et al: Dosimetric Predictors of Laryngeal Edema. International Journal of Radiation Oncology Biology Physics 2007, 68:741-749.

9. Caglar HB, Tishler RB, Othus M, et al: Dose to Larynx Predicts for Swallowing Complications After Intensity-Modulated Radiotherapy. International Journal of Radiation Oncology Biology Physics 2008, 72:1110-1118.

10. Fang F-M, Chien C-Y, Tsai W-L, et al: Quality of Life and Survival Outcome for Patients With Nasopharyngeal Carcinoma Receiving ThreeDimensional Conformal Radiotherapy vs. Intensity-Modulated Radiotherapy-A Longitudinal Study. International Journal of Radiation Oncology Biology Physics 2008, 72:356-364.

11. Fu KK, Pajak TF, Trotti A, et al: A Radiation Therapy Oncology Group (RTOG) phase III randomized study to compare hyperfractionation and two variants of accelerated fractionation to standard fractionation radiotherapy for head and neck squamous cell carcinomas: first report of RTOG 9003. Int J Radiat Oncol Biol Phys 2000, 48:7-16.

12. Forastiere $A A$, Goepfert $H$, Maor $M$, et al: Concurrent Chemotherapy and Radiotherapy for Organ Preservation in Advanced Laryngeal Cancer. N Engl J Med 2003, 349:2091-2098.

13. Eisbruch A, Lyden T, Bradford CR, et al: Objective assessment of swallowing dysfunction and aspiration after radiation concurrent with chemotherapy for head-and-neck cancer. International Journal of Radiation Oncology Biology Physics 2002, 53:23-28.

14. de Arruda FF, Puri DR, Zhung J, et al: Intensity-modulated radiation therapy for the treatment of oropharyngeal carcinoma: the Memoria Sloan-Kettering Cancer Center experience. Int J Radiat Oncol Biol Phys 2006, 64:363-373.

15. Teguh DN, Levendag PC, Noever I, et al: Treatment techniques and site considerations regarding dysphagia-related quality of life in cancer of the oropharynx and nasopharynx. Int J Radiat Oncol Biol Phys 2008, 72:1119-1127.

16. Dirix P, Nuyts S: Value of Intensity-Modulated Radiotherapy in Stage IV Head-and-neck Squamous Cell Carcinoma. International Journal of Radiation Oncology*Biology*Physics 2010, 78:1373-1380.

17. Lee NY, de Arruda FF, Puri DR, et al: A comparison of intensity-modulated radiation therapy and concomitant boost radiotherapy in the setting of concurrent chemotherapy for locally advanced oropharyngeal carcinoma. Int J Radiat Oncol Biol Phys 2006, 66:966-974.

18. Fua TF, Corry J, Milner AD, Cramb J, Walsham SF, Peters LJ: Intensitymodulated radiotherapy for nasopharyngeal carcinoma: Clinical correlation of dose to the pharyngo-esophageal axis and dysphagia. International Journal of Radiation Oncology*Biology*Physics 2007, 67:976-981.

19. Huguenin P, Beer KT, Allal A, et al: Concomitant Cisplatin Significantly Improves Locoregional Control in Advanced Head and Neck Cancers Treated With Hyperfractionated Radiotherapy. J Clin Oncol 2004, 22:4665-4673.

20. Caudell JJ, Schaner PE, Desmond RA, Meredith RF, Spencer SA, Bonner JA: Dosimetric Factors Associated With Long-Term Dysphagia After Definitive Radiotherapy for Squamous Cell Carcinoma of the Head and Neck. International Journal of Radiation Oncology*Biology*Physics 2010, 76:403-409.

21. Feng FY, Kim HM, Lyden TH, et al: Intensity-Modulated Radiotherapy of Head and Neck Cancer Aiming to Reduce Dysphagia: Early Dose-Effect Relationships for the Swallowing Structures. International Journal of Radiation Oncology Biology Physics 2007, 68:1289-1298.

22. Studer G, Peponi E, Kloeck S, Dossenbach T, Huber G, Glanzmann C: Surviving Hypopharynx-Larynx Carcinoma in the Era of IMRT. International Journal of Radiation Oncology*Biology*Physics 2010, 77:1391-1396.

23. Langendijk JA, Doornaert $P$, Rietveld DHF, Verdonck-de Leeuw IM, René Leemans C, Slotman BJ: A predictive model for swallowing dysfunction after curative radiotherapy in head and neck cancer. Radiotherapy and Oncology 2009, 90:189-195

24. Joke W, Kim De R, Duprez F, et al: Acute Normal Tissue Reactions in Head-and-Neck Cancer Patients Treated With IMRT: Influence of Dose and Association With Genetic Polymorphisms in DNA DSB Repair Genes. International journal of radiation oncology, biology, physics 2009, 73:1187-1195. 
25. Chao KSC, Gokhan O, Wade LT: Toxicity profile of intensity-modulated radiation therapy for head and neck carcinoma and potential role of amifostine. Seminars in oncology 2003, 30:101-108.

26. Denis F, Garaud P, Bardet $E$, et al: Late toxicity results of the GORTEC 9401 randomized trial comparing radiotherapy with concomitant radiochemotherapy for advanced-stage oropharynx carcinoma: comparison of LENT/SOMA, RTOG/EORTC, and NCI-CTC scoring systems. International Journal of Radiation Oncology Biology Physics 2003, 55:93-98.

doi:10.1186/1748-717X-6-1

Cite this article as: Peponi et al:: Dysphagia in head and neck cancer patients following intensity modulated radiotherapy (IMRT). Radiation Oncology 2011 6:1

Submit your next manuscript to BioMed Central and take full advantage of:

- Convenient online submission

- Thorough peer review

- No space constraints or color figure charges

- Immediate publication on acceptance

- Inclusion in PubMed, CAS, Scopus and Google Scholar

- Research which is freely available for redistribution

Submit your manuscript at www.biomedcentral.com/submit
Ciomed Central 